\title{
Incomplete colonoscopy: Maximizing completion rates of gastroenterologists
}

\author{
Mayur Brahmania MD, Jei Park MD, Sigrid Svarta MD, Jessica Tong BSc, Ricky Kwok BSc, Robert Enns MD
}

\begin{abstract}
M Brahmania, J Park, S Svarta, J Tong, R Kwok, R Enns. Incomplete colonoscopy: Maximizing completion rates of gastroenterologists. Can J Gastroenterol 2012;26(9):589-592.
\end{abstract}

BACKGROUND: Cecal intubation is one of the goals of a quality colonoscopy; however, many factors increasing the risk of incomplete colonoscopy have been implicated. The implications of missed pathology and the demand on health care resources for return colonoscopies pose a conundrum to many physicians. The optimal course of action after incomplete colonoscopy is unclear.

OBJECTIVES: To assess endoscopic completion rates of previously incomplete colonoscopies, the methods used to complete them and the factors that led to the previous incomplete procedure.

METHODS: All patients who previously underwent incomplete colonoscopy (2005 to 2010) and were referred to St Paul's Hospital (Vancouver, British Columbia) were evaluated. Colonoscopies were re-attempted by a single endoscopist. Patient charts were reviewed retrospectively.

RESULTS: A total of 90 patients (29 males) with a mean ( \pm SD) age of $58 \pm 13.2$ years were included in the analysis. Thirty patients $(33 \%)$ had their initial colonoscopy performed by a gastroenterologist. Indications for initial colonoscopy included surveillance or screening (23\%), abdominal pain (15\%), gastrointestinal bleeding (29\%), change in bowel habits or constitutional symptoms (18\%), anemia (7\%) and chronic diarrhea (8\%). Reasons for incomplete colonoscopy included poor preparation $(11 \%)$, pain or inadequate sedation $(16 \%)$, tortuous colon $(30 \%)$, diverticular disease $(6 \%)$, obstructing mass $(6 \%)$ and stricturing disease $(10 \%)$. Reasons for incomplete procedures in the remaining $21 \%$ of patients were not reported by the referring physician. Eighty-seven (97\%) colonoscopies were subsequently completed in a single attempt at the institution. Seventy-six (84\%) colonoscopies were performed using routine manoeuvres, patient positioning and a variable-stiffness colonoscope (either standard or pediatric). A standard 160 or 180 series Olympus gastroscope (Olympus, Japan) was used in five patients $(6 \%)$ to navigate through sigmoid diverticular disease; a pediatric colonoscope was used in six patients (7\%) for similar reasons. Repeat colonoscopy on the remaining three patients $(3 \%)$ failed: all three required surgery for strictures (two had obstructing malignant masses and one had a severe benign obstructing sigmoid diverticular stricture).

CONCLUSION: Most patients with previous incomplete colonoscopy can undergo a successful repeat colonoscopy at a tertiary care centre with instruments that are readily available to most gastroenterologists. Other modalities for evaluation of the colon should be deferred until a second attempt is made at an expert centre.

Key Words: Barium enema; Colonoscopy; CT colonography; Doubleballoon enteroscopy; Incomplete colonoscopy

Since its introduction in the late 1960s, the technology of colonos$\checkmark$ copy has progressed rapidly, as has the technological success of experienced endoscopists $(1,2)$. Cecal intubation is one of the main goals of colonoscopy; however, complete colonoscopy rates vary considerably. Incomplete colonoscopies pose a clinical concern because

\section{Les coloscopies incomplètes : maximiser les taux de complétion par les gastroentérologues}

HISTORIQUE : L'intubation cæcale est l'un des objectifs d'une coloscopie de qualité, mais de nombreux facteurs qui accroissent le risque de coloscopies incomplètes entrent en jeu. Les répercussions d'une pathologie non diagnostiquée et l'utilisation d'effectifs de santé importants pour reprendre les coloscopies posent un dilemme à de nombreux médecins. Le mode d'action optimal après une coloscopie incomplète n'est toujours pas clair.

OBJECTIFS : Évaluer les taux de complétion des endoscopies après des coloscopies incomplètes, les méthodes utilisées pour les effectuer et les facteurs responsables de l'intervention incomplète.

MÉTHODOLOGIE : Les chercheurs ont évalué tous les patients qui ont déjà subi une coloscopie incomplète entre 2005 et 2010 et qui ont été aiguillés au St Paul's Hospital de Vancouver, en Colombie-Britannique. Un seul endoscopiste a repris les coloscopies. Les chercheurs ont procédé à un examen rétrospectif des dossiers des patients.

RÉSULTATS : Au total, 90 patients (dont 29 hommes) d'un âge moyen ( \pm ÉT) de $58 \pm 13,2$ ans ont été inclus dans l'analyse. Un gastroentérologue avait effectué la première coloscopie de 30 patients (33\%). Les indications justifiant cette première coloscopie étaient la surveillance ou le dépistage $(23 \%)$, des maux de ventre $(15 \%)$, un saignement gastrointestinal (29\%), des modifications aux habitudes intestinales ou des symptômes constitutionnels (18 \%), de l'anémie (7 \%) et une diarrhée chronique $(8 \%)$. Les raisons de la coloscopie incomplète étaient une mauvaise préparation (11\%), de la douleur ou une sédation insuffisante (16\%), un côlon tortueux (30\%), une diverticulose (6 \%), une masse obstructive $(6 \%)$ et une maladie sténosante(10\%). Le médecin traitant n'avait pas précisé la raison de l'intervention incomplète des $21 \%$ de patients restants. L'endoscopiste a ensuite effectué 87 coloscopies (97\%) en une seule tentative à l'établissement. Il en a exécuté 76 (84\%) au moyen des manœuvres habituelles, grâce à la position du patient et à des coloscopes de diverses rigidités (standard ou pédiatrique). Chez cinq patients $(6 \%)$, il a utilisé un gastroscope Olympus standard de série 160 ou 180 (Olympus, Japon) pour procéder à l'examen malgré une diverticulose sigmoïdienne, et chez six patients $(7 \%)$, il a utilisé un coloscope pédiatrique pour des raisons similaires. La reprise de la coloscopie chez les trois autres patients (3\%) a échoué : les trois ont dû être opérés pour des sténoses (deux avaient des masses obstructives malignes et un, une importante sténose sigmoïdienne obstructive bénigne d'origine diverticulaire).

CONCLUSION : La plupart des patients ayant été soumis à une coloscopie incomplète peuvent subir une reprise réussie de la coloscopie dans un centre de soins tertiaires, au moyen d'instruments auxquels la plupart des gastroentérologues ont facilement accès. Il faudrait reporter les autres modalités d'évaluation du côlon en attendant une deuxième tentative dans un centre spécialisé.

management strategies to assess patients with incomplete colonoscopies vary. For radiological assessment following incomplete procedures, double-contrast barium enema (DCBE) was commonly used in the past; however, it has now been replaced by computed tomography colonography (CTC) in many centres (3). CTC has come to the

Department of Medicine, Division of Gastroenterology, St Paul's Hospital, University of British Columbia, Vancouver, British Columbia

Correspondence: Dr Robert Enns, Suite 770, 1190 Hornby Street, Vancouver, British Columbia V6Z 2K5. Telephone 604-688-6332 ext 222,

fax604-689-2004,e-mail rob.enns@ubc.ca

Received for publication October 1, 2011. Accepted December 20, 2011 


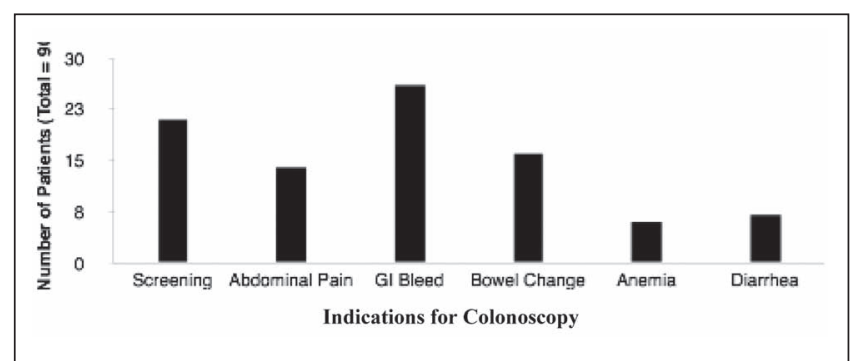

Figure 1) Indications for initial colonoscopic evaluation. GI Gastrointestinal

forefront in the past decade, but problems with limited sensitivity and lack of mucosal detail for vascular lesions often lead to repeat colonoscopy attempts. Repeat endoscopic studies can now use several different techniques involving variable-stiffness instruments (pediatric and adult), enteroscopes (balloon and nonballoon types) and gastroscopes (for those with sigmoid strictures) (4-11). In an ideal setting, a failed colonoscopy should be completed in a procedure offering high sensitivity and therapeutic potential to give adequate assurance to the patient. In addition, it should offer the longest interval before the necessity of repeating the study, which currently is best offered by conventional colonoscopy. The purpose of the present study was to review the factors leading to colonoscopy failures and to analyze our methods and success rates for completing previously failed colonoscopies.

\section{METHODS}

The colonoscopy reports of all patients undergoing colonoscopy by a single endoscopist (RE) from 2005 to 2010 at St Paul's Hospital in Vancouver, British Columbia, were reviewed. St Paul's Hospital is affiliated with the University of British Columbia (Vancouver, British Columbia) and is a tertiary referral centre for advanced endoscopic procedures and successfully performs approximately 10,000 colonoscopies per year with a $97 \%$ completion rate. The primary endoscopist in the present study (RE) has a crude completion rate of $99.6 \%$, performing approximately 1000 colonoscopies/year. Patients with incomplete colonoscopy were identified by systematically reviewing computerized medical records of patients who underwent colonoscopy. No colonoscopy was performed at our institution before re-attempt. The inclusion criteria were an incomplete colonoscopy and referral to one gastrointestinal (GI) specialist (RE). All colonoscopies were re-attempted by a single gastroenterologist (RE). Repeat colonoscopies performed by other gastroenterologists at our institution were not analyzed or included in the present study. Procedures were performed between 07:30 to 11:30, and bowel preparation was achieved using Pico-Salax (Ferring Pharmaceuticals Inc, Canada). A standard 180 series Olympus (Olympus, USA) adult colonoscope was used for all cases initially. Patients were sedated with intravenous doses of $2 \mathrm{mg}$ midazolam and $50 \mu \mathrm{g}$ fentanyl, which were titrated to patient comfort. The patients' heart rate and oxygen saturation were monitored throughout the procedure. Routine manoeuvres (ie, air insufflation, water cleanse) and change of patient position were used to advance the colonoscope as necessary. All patients were scheduled into a standard $30 \mathrm{~min}$ endoscopy slot. Complete colonoscopy was defined as visualisation and intubation of the cecum, confirmed by identification of the ileocecal valve and triradiate fold. Details of the first endoscopist, place of original endoscopy, patient sex, reason for incomplete colonoscopy and steps taken to complete colonoscopy (if applicable) were noted. Results are presented in descriptive statistics. Means and SDs are used to report continuous variables following a normal distribution, and median (range) are used to report non-normal continuous variables. The study was approved in writing by the local ethics committee and conducted according to the Declaration of Helsinki.

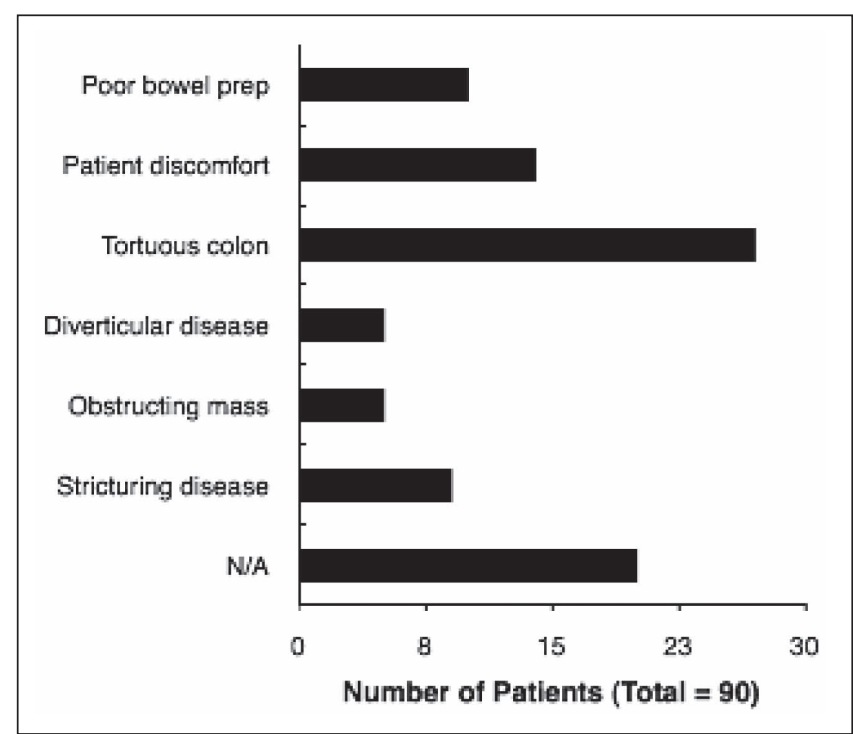

Figure 2) Reasons for incomplete colonoscopy. N/A Not applicable; prep Preparation

\section{RESULTS}

Ninety patients (mean $[ \pm$ SD] age $58 \pm 13.2$ years, $32 \%$ male) were included in the analysis. Thirty patients $(33 \%)$ had their initial colonoscopy performed by a gastroenterologist in a nonacademic institution. The remainder of the incomplete colonoscopies were performed by general surgeons and internal medicine specialists in both academic and nonacademic hospitals. Indications for initial colonoscopic evaluation included surveillance or screening (23\%) (either colorectal cancer or inflammatory bowel disease), abdominal pain not yet diagnosed (15\%), GI bleeding (29\%), change in bowel habits or constitutional symptoms (18\%), anemia not yet diagnosed $(7 \%)$ and chronic diarrhea (8\%) (Figure 1). Reasons for incomplete colonoscopy included poor preparation (11\%), patient discomfort (16\%), tortuous or redundant colon $(30 \%)$, diverticular disease $(6 \%)$, obstructing mass $(6 \%)$ and stricturing disease (10\%) (Figure 2). No reason for the incomplete procedures was reported for the remaining $21 \%$ of patients. Eighty-seven colonoscopies were subsequently completed at St Paul's Hospital, with a crude completion rate of $96.8 \%$. Seventy-six (84\%) were performed using routine manoeuvres, patient positioning and a standard 180 series Olympus colonoscope. A standard 160 - or 180 -series Olympus gastroscope was used in five patients (6\%) to navigate through sigmoid diverticular disease; a pediatric colonoscope was used in six patients (7\%) for similar reasons (Table 1). An overtube or an enteroscope was not used. No procedures were performed under fluoroscopy. No patients required sedation doses exceeding what gastroenterologists would deem acceptable and, similarly, propofol was not used. All patients had their re-attempted colonoscopy performed within a mean of $30 \pm 5 \mathrm{~min}$. No complications occurred during repeat colonoscopy. Colonoscopy on the remaining three patients $(3 \%)$ failed because two had a malignant obstructing mass and one had a severe diverticular stricturing disease; none of these strictures would permit passage of a standard gastroscope. All three required surgical intervention, with surveillance of the remaining colon performed after surgery.

\section{DISCUSSION}

The importance of an incomplete colonoscopy poses a diagnostic dilemma for many endoscopists. The reported rate of incomplete colonoscopies ranges from $4 \%$ to $25 \%$ according to published reports $(12-15)$, and increases with age up to a rate of $22 \%$ to $33 \%$ (16). Reasons for incomplete colonoscopy have been reported in previous studies and include redundant or tortuous colon (particularly sigmoid colon), marked diverticular disease, obstructing masses and strictures, angulation or fixation of colonic loops, adhesions due to previous 
surgery, spasm, poor colonic preparation, female sex or older age, and a low body mass index (17-19). Furthermore, Sanaka et al (20) found operator fatigue to play an important role because colonoscopies performed later in the day had higher rates of incompletion. In the largest study to date comparing colonoscopies performed at a tertiary care centre with those performed at community hospitals or in private offices, Shah et al (21) reported a higher failure rate in colonoscopies performed elsewhere versus those performed at a tertiary care centre. Subsequently, numerous techniques have been used to complete previous incomplete colonoscopies including lumbar epidural analgesia, use of a gastroscope, external straightener (ie, overtube) and a pediatric colonoscope, with all having varying success $(4-7,22)$.

Nevertheless, other methods, such as DCBE, have been proposed as an alternative choice to evaluate the colon after incomplete colonoscopy. Due to its noninvasive nature and the ease of access associated with DCBE, it was regarded as a viable option. However, two largescale prospective studies have shown DCBE to have low accuracy in detecting colonic neoplasms, with sensitivity for adenomas $>9 \mathrm{~mm}$ in size in the range of $45 \%$ to $50 \%(23-25)$. Given the false-positive rate of $5 \%$ to $10 \%$ reported in the literature for polyps $>1 \mathrm{~cm}$ in size, the need for repeat colonoscopy when lesions are found on barium images in the nonvisualized colon unnecessarily increase the cost of the diagnostic work-up in a small percentage of patients (26).

CTC is accurate in detecting colorectal neoplasms, as reported in meta-analyses $(27,28)$, revealing sensitivities in the range of $85 \%$ to $90 \%$, and specificities of approximately $95 \%$ for polyps $>9 \mathrm{~mm}$ in size. In addition, several studies have shown CTC to be a valuable tool in evaluating the proximal colon after incomplete colonoscopy (29-34). Furthermore, the American Gastroenterologists Association has recognized the role of CTC in adults who fail colonoscopy (3). However, most of these studies evaluated CTC in the context of colorectal cancer detection (ie, screening), which as shown in our study, does not comprise most of our incomplete colonoscopies. The majority of our patients had significant symptoms and, therefore, a higher prevalence of disease and higher likelihood of requiring endoscopic intervention. This high prevalence of pathology mandates endoscopic therapeutic intervention not available through CTC. The role of CTC is limited, particularly in the setting of lower GI bleeding. In some cases, colonic collapse or repletion by fluid or feces may preclude evaluation of the rectum, sigmoid or descending colon. Subsequently, a significant number of false positives may result, which inevitably leads to repeat colonoscopy. Additionally, guidelines for average-risk patients undergoing CTC are presently at five years, whereas those with optical colonoscopy are at 10 years (35). Provided that colonoscopy can be completed safely at an expert centre, it appears that therapy and diagnosis can be achieved while providing the longest interval between repeat procedures, resulting in ideal resource use.

Initially designed for deep and even complete intubation of the small bowel, double-balloon enteroscopy (DBE) has played a role in incomplete colonoscopy. Technically more flexible and narrow, DBE enables the user to navigate through acute angulations and redundant colon effectively and easily while preventing the colon from looping on itself, and still offering the advantage of therapeutic intervention. Several studies have demonstrated the efficacy of DBE in completing previously incomplete colonoscopies, with success rates in the range of $88 \%$ to $97 \%(4-7)$. However, procedure time (average $50.6 \mathrm{~min}$ ), endoscopist expertise and staffing (one assistant to help with the procedure and another for patient monitoring) required to perform DBE are major drawbacks. Until mechanical and technical refinements are made to this relatively new modality, effort and cost utility would not be preferred over repeating colonoscopy in the long term.

Our study, although similar in many aspects to previous studies, highlights other key points not mentioned that may be useful for endoscopists. Whereas previous analyses of incomplete studies primarily investigated screening or surveillance for colorectal cancer, our study recognized other reasons for which colonoscopy was used because there are other pathologies aside from colorectal cancer affecting
TABLE 1

Techniques used to complete previously incomplete colonoscopies

\begin{tabular}{lc}
\hline Technique & Patients, $\mathbf{n}(\%)$ \\
\hline Total & $90(100)$ \\
Routine manoeuvres* & $76(84)$ \\
Gastroscope & $5(6)$ \\
Pediatric colonoscope & $6(7)$ \\
Failed completion of repeat colonoscopy & $3(3)$ \\
\hline
\end{tabular}

*Standard preparation/sedation/colonoscope/patient positioning

patient morbidity and mortality (Figure 1). Only 21 (23\%) of our patients underwent their initial colonoscopy for surveillance or screening purposes. Furthermore, our study highlights another aspect of care, namely, repeat colonoscopies should be performed at a tertiary care centre by an experienced gastroenterologist who may have the available techniques and perhaps more experienced nursing staff to complete challenging colonoscopies. In the present study, more than $95 \%$ of colonoscopies were completed because only those limited by strictures (both benign and malignant) were incomplete. No advanced techniques of enteroscopy or fluoroscopy were used. Endoscopy units must be aware that simple methods for completion of procedures in many settings, including titrated sedation and appropriate allotment of time, are adequate as opposed to considering new and relatively expensive alternatives that may not offer the same advantages.

Our study has limitations that we acknowledge. First, the experience of the endoscopists performing the initial colonoscopy was not known, which may or may not have contributed to higher incompletion rates. Similarly, only one endoscopist at our institution (RE) performs repeat colonoscopies and the high completion rate may reflect the skill of the endoscopist; however, we believe that the techniques used to complete our procedures are within the capabilities of most gastroenterologists practicing in a tertiary care centre. Second, we acknowledge that specific sedation requirements were not recorded in the initial colonoscopy; therefore, enhanced patient comfort at our institution may have allowed for better completion rates. Finally, our institution uses Pico-Salax as its bowel preparation and, although it was difficult to determine what preparation solution was used for the initial incomplete colonoscopy, we believe that rather than preparation being the problem, patient compliance/factors may have played a role.

\section{CONCLUSION}

Our study highlights issues regarding previously incomplete colonoscopies. With appropriate expertise and readily available endoscopic instrumentation, $95 \%$ of previously incomplete colonoscopies can be completed by a gastroenterologist at a tertiary care centre. Other modalities of investigating the colon (CTC, DCBE, balloon enteroscopy) are rarely required in this setting. We recommend that regional sites develop specific expertise in endoscopic capabilities so the number of incomplete procedures can be minimized. Additionally, all sites should ensure that targets for procedure completion rates, as suggested by numerous regional authorities, are being met, and that quality initiatives encourage ongoing assessment and improvement in these parameters.

DISCLOSURES: The authors have no financial disclosures or conflicts of interest to declare.

\section{REFERENCES}

1. Sivak M. Polypectomy: Looking back. Gastrointest Endosc 2004;60:977-82.

2. Rex DK, Petrini JL, Baron TH, et al. Quality indicators for colonoscopy. Gastrointest Endosc 2006;63(Suppl 4):S16-28.

3. Rockey DC, Barish M, Brill JV, et al. Standards for gastroenterologists for performing and interpreting diagnostic 
computed tomographic colonography. Gastroenterology 2007;133:1005-24.

4. Kaltenbach T, Soetikno R, Friedland S. Use of double balloon enteroscope facilitates caecal intubation after incomplete colonoscope with a standard colonoscope. Dig Liver Dis 2006;38:921-5.

5. Pasha SF, Harrison ME, Das A, Corrado CM, Arnell KN, Leighton JA. Utility of double-balloon colonoscopy for completion of colon examination after incomplete colonoscopy with conventional colonoscope. Gastrointest Endosc 2007;65:848-53.

6. Gay G, Delvaux M. Double-balloon colonoscopy after failed conventional colonoscopy: A pilot series with a new instrument. Endoscopy 2007;39:788-92.

7. Moreels TG, Pelckmans PA. Double-balloon endoscope for failed conventional colonoscopy. Clin Gastroenterol Hepatol 2008;6:259.

8. Dafnis G, Blomqvist P, Pahlman L, Ekbom A. The introduction and development of colonoscopy within a defined population in Sweden. Scand J Gastroenterol 2000;35:765-71.

9. Lichtenstein GR, Park PD, Long WB, Ginsberg GG, Kochman ML. Use of a push enteroscope improves ability to perform total colonoscopy in previously unsuccessful attempts at colonoscopy in adult patients. Am J Gastroenterol 1999;94:187-90.

10. Rex DK, Chen SC, Overhiser AJ. Colonoscopy technique in consecutive patients referred for prior incomplete colonoscopy. Clin Gastroenterol Hepatol 2007;5:879-83.

11. Paonessa NJ, Rosen L, Stasik JJ. Using the gastroscope for incomplete colonoscopy. Dig Liver Dis 2005;37:113-8.

12. Anderson ML, Heigh RI, McCoy GA, et al. Accuracy of assessment of the extent of examination by experienced colonoscopists. Gastrointest Endosc 1992;38:560-3.

13. Marshall JB, Barthel JS. The frequency of total colonoscopy and terminal ileal intubation in the 1990s. Gastrointest Endosc 1993;39:518-20.

14. Winawer SJ, Fletcher RH, Miller L, et al. Colorectal cancer screening: Clinical guidelines and rationale. Gastroenterology 1997;112:594-642.

15. Burtin P, Bour B, Charlois T, et al. Colonic investigations in the elderly: Colonoscopy or barium enema? Aging 1995;7:190-4.

16. Cady B, Persson AV, Monson DO, Maunz DL. Changing patterns of colorectal carcinoma. Cancer 1974;33:422-6.

17. Cirocco WC, Rusin LC. Factors that predict incomplete colonoscopy. Dis Colon Rectum 1995;38:964-8.

18. Granath F, Påhlman L, Ekbom A, Blomqvist P. Patient factors influencing the completion rate in colonoscopy. Dig Liver Dis 2005;37:113-8.

19. Anderson JC, Gonzalez JD, Messina CR, Pollack BJ. Factors that predict incomplete colonoscopy: Thinner is not always better. Am J Gastroenterol 2000;95:2784-7.

20. Sanaka MR, Shah N, Mullen KD, Ferguson DR, Thomas C, McCullough AJ. Afternoon colonoscopies have higher failure rates than morning colonoscopies. Am J Gastroenterol 2000;95:2784-7.
21. Shah H, Paszat L, Saskin R, Stukel T, Rabeneck L. Factors associated with incomplete colonoscopy: A population-based study. Gastroenterology 2007;132:2297-303.

22. Bleiberg H, Deloof T, Ewalenko P, Vandesteene A, Beyens M, Tremblez A. Is lumbar epidural analgesia an alternative in patients who have incomplete colonoscopy with standard premedication? Gastrointest Endosc 1982;28:240-2.

23. Winawer SJ, Stewart ET, Zauber AG, et al. A comparison of colonoscopy and double-contrast barium enema for surveillance after polypectomy. National Polyp Study Work Group. N Engl J Med 2000;342:1766-72.

24. Rockey DC, Paulson E, Niedzwiecki D, et al. Analysis of air contrast barium enema, computed tomographic colonography, and colonoscopy: Prospective comparison. Lancet 2005;365:305-11.

25. Chong A, Shah JN, Levine MS, et al. Diagnostic yield of barium enema examination after incomplete colonoscopy. Radiology 2002;223:620-4.

26. Glick S, Wagner JL, Johnson CD. Cost-effectiveness of double-contrast barium enema in screening for colorectal cancer. AJR Am J Roentgenol 1998;170:629-36.

27. Halligan S, Altman DG, Taylor SA, et al. CT colonography in the detection of colorectal polyps and cancer: Systematic review, meta-analysis, and proposed minimum data set for study level reporting. Radiology 2005;237:893-904.

28. Mulhall BP, Veerappan GR, Jackson JL. Meta-analysis: Computed tomographic colonography. Ann Intern Med 2005;142:635-50.

29. Macari M, Berman P, Dicker M, Milano A, Megibow AJ. Usefulness of CT colonography in patients with incomplete colonoscopy. AJR Am J Roentgenol 1999;173:561-4.

30. Morrin MM, Kruskal JB, Farrell RJ, Goldberg SN, McGee JB, Raptopoulos V. Endoluminal CT colonography after an incomplete endoscopic colonoscopy. AJR Am J Roentgenol 1999;172:913-8.

31. Neri E, Giusti P, Battolla L, et al. Colorectal cancer: Role of CT colonography in preoperative evaluation after incomplete colonoscopy. Radiology 2002;223:615-9.

32. Gryspeerdt S, Lefere P, Herman M, et al. CT colonography with fecal tagging after incomplete colonoscopy. Eur Radiol 2005;15:1192-202.

33. Copel L, Sosna J, Kruskal JB, Raptopoulos V, Farrell RJ, Morrin MM. CT colonography in 546 patients with incomplete colonoscopy. Radiology 2007;244:471-78.

34. Rockey DC, Barish M, Brill JV, et al. Standards for gastroenterologists for performing and interpreting diagnostic computed tomographic colonography. Gastroenterology 2007; 133:1005-24.

35. Levin B, Lieberman DA, McFarland B, et al. Screening and surveillance for the early detection of colorectal cancer and adenomatous polyps, 2008: A joint guideline from the American Cancer Society, the US Multi-Society Task Force on Colorectal Cancer, and the American College of Radiology. CA Cancer J Clin 2008;58:130-60. 


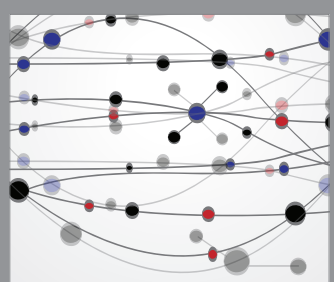

The Scientific World Journal
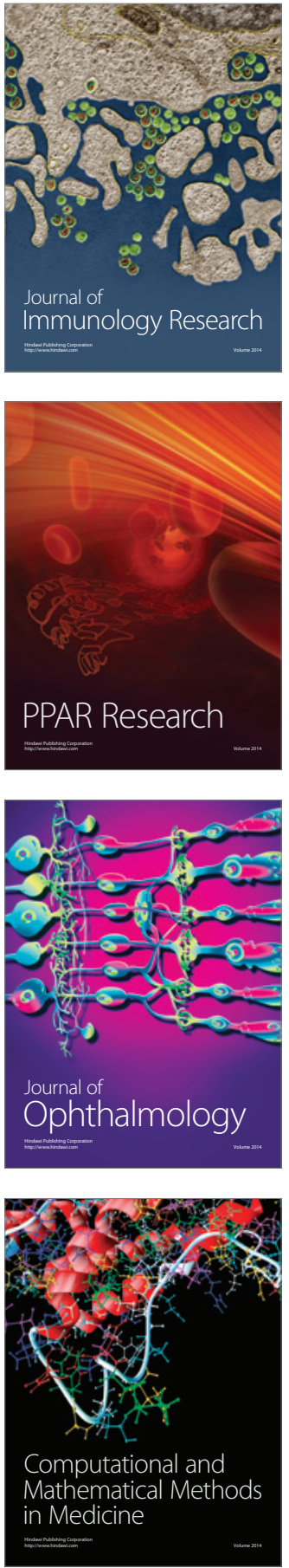

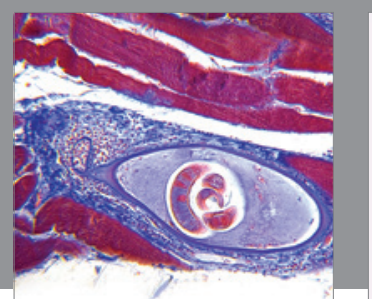

Gastroenterology Research and Practice

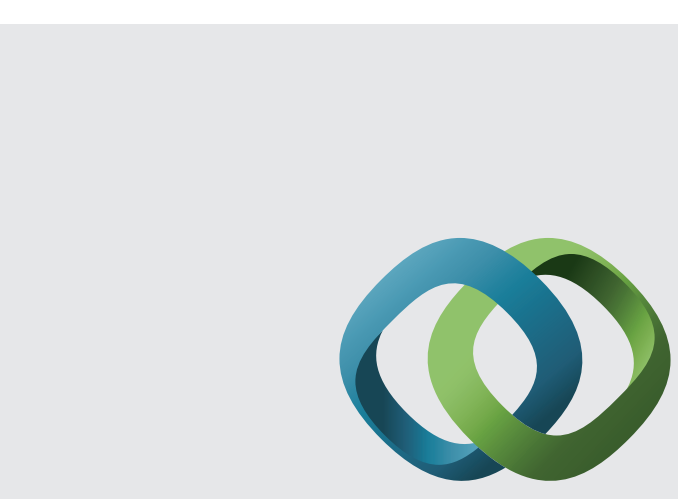

\section{Hindawi}

Submit your manuscripts at

http://www.hindawi.com
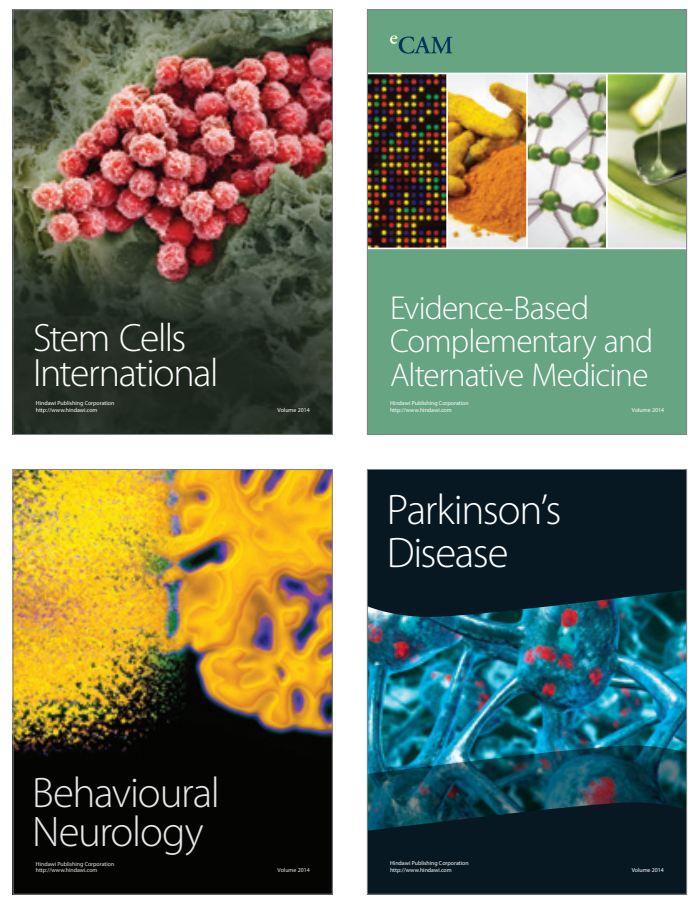
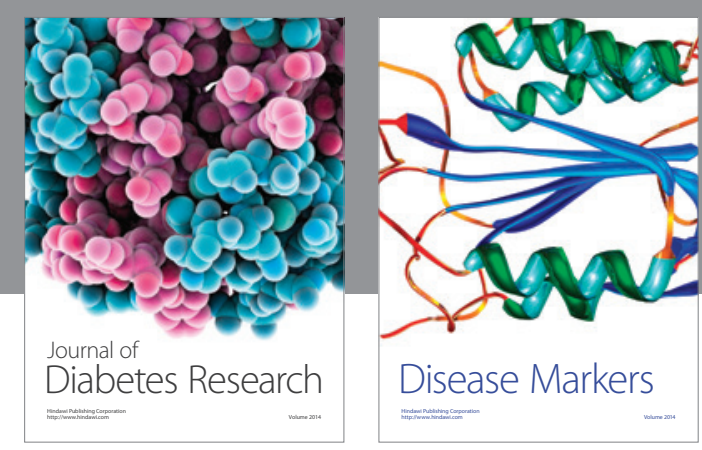

Disease Markers
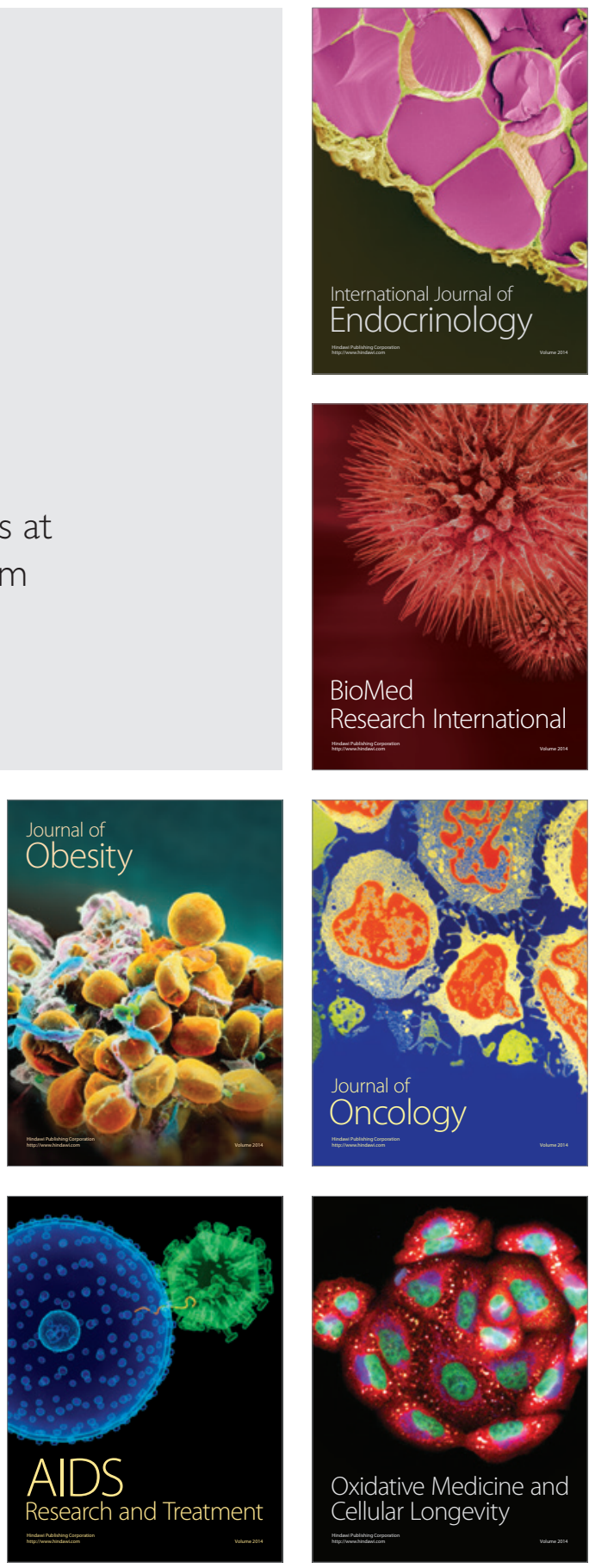